\title{
Monozygotic vanishing twin after single euploid blastocyst transfer
}

\author{
Nirali Shah, ${ }^{1}$ Cosima Neumann, ${ }^{2}$ Nigel Pereira ${ }^{3}$
}

'Department of Obstetrics and Gynecology, NewYorkPresbyterian Hospital, Weill Cornell Medicine, New York, New York, USA

${ }^{2}$ Weill Cornell Medicine-Qatar, Education City, Qatar

${ }^{3}$ The Ronald 0 Perelman and Claudia Cohen Center for Reproductive Medicine, Weill Cornell Medicine, New York, New York, USA

Correspondence to Dr Nigel Pereira; nip9060@med.cornell.edu

Accepted 2 June 2020

\section{DESCRIPTION}

A 33-year-old gravida 0 woman with a 15 -month history of involuntary infertility presented to the office for an infertility consultation. Her menstrual history was unremarkable. Her hysterosalpingogram and ovarian reserve testing was normal. Her partner's semen analysis was within normal limits. She was diagnosed with unexplained infertility and underwent four clomiphene citrate-intrauterine insemination cycles; however, none of these cycles resulted in a pregnancy. She subsequently underwent in vitro fertilisation (IVF) with preimplantation genetic testing of embryos for aneuploidy (PGT-A).

A single euploid blastocyst was transferred in a leuprolide acetate-based programmed frozen embryo cycle (figure 1A). The embryo transfer occurred 6 months after the IVF cycle and 8 months after the last clomiphene citrate-intrauterine insemination cycle. Her serum $\beta$-human chorionic gonadotropin level 10 days after the embryo transfer was $203 \mathrm{mIU} / \mathrm{mL}$. Transvaginal ultrasonography on cycle day 35 showed a single intrauterine gestational sac (figure 1B). Transvaginal ultrasonography was repeated in 10 days due to symptoms of vaginal bleeding and cramping. Two distinct gestational sacs were noted, each with a small fetal pole (figure 2). Cardiac activity was noted in both fetal poles (89 beats/min and 109 beats/min). She remained asymptomatic for the next 2 weeks. Her final transvaginal ultrasonogram at cycle day 59 (8 weeks and 2 days) demonstrated two gestational sacs, both with fetal poles. However, one fetal pole was smaller (crownrump length of $5.23 \mathrm{~mm}, 6$ weeks and 2 days) and without cardiac activity (figure $3 \mathrm{~A}$ ). The second fetal pole's crown-rump length measurement of $17.59 \mathrm{~mm}$ ( 8 weeks and 2 days) was consistent with the actual gestational age (figure $3 \mathrm{~B}$ ). This fetal pole also had cardiac cavity of 167 beats/min. The smaller fetal pole was not visualised during later obstetric ultrasonograms. The patient delivered

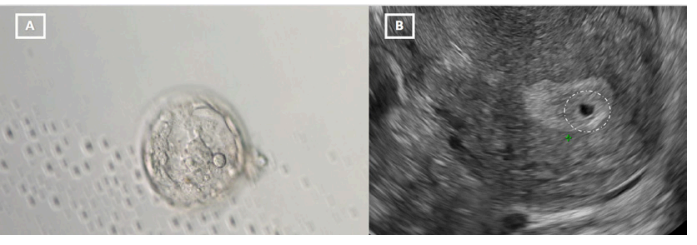

Figure 1 (A) Microscopic image of the transferred single euploid embryo; (B) transvaginal ultrasonography, sagittal section shows a single intrauterine gestational sac (dotted white circle).

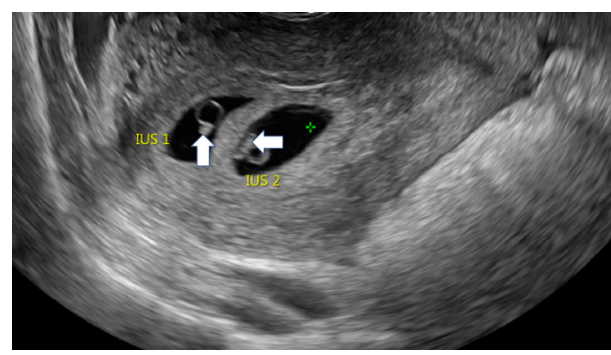

Figure 2 Two intrauterine gestational sacs IUS 1 and IUS 2 are noted. The individual fetal poles are indicated by the solid white arrows.

a healthy female singleton weighing 2255 g at 37 weeks of gestation.

The current case highlights monozygotic twinning after a single blastocyst transfer and subsequent vanishing of one twin. Dizygotic twinning is more common in pregnancies conceived via IVF, primarily due to the transfer of multiple embryos. However, recent studies have noted an increased risk of monozygotic twinning in IVF pregnancies when compared with the general population, even in the setting of single embryo transfers. A 2015 study evaluated 28596 pregnancies after single embryo transfers between 2003 and 2012 and reported an overall incidence of $2.24 \%$ for monozygotic twinning. ${ }^{1}$ The study also suggested a higher incidence of monozygotic twinning with blastocyst transfers compared with cleavage-stage embryos. An independent study of 937848 single embryo transfers in Japan indicated that frozen embryo cycles and blastocyst transfers were independently associated with monozygotic twinning. ${ }^{2}$ While vanishing twins

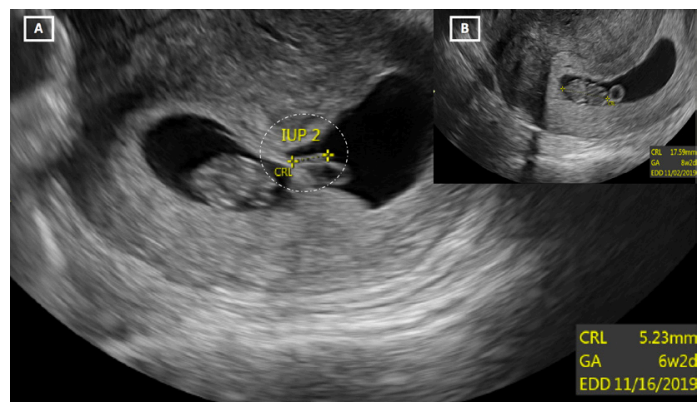

Figure 3 (A) Transvaginal ultrasonography shows a smaller intrauterine pregnancy (IUP 2) with a crownrump length measurement of $5.23 \mathrm{~mm}$ (dotted white circle). No cardiac activity was noted. (B) Transvaginal ultrasonography shows a normal IUP (yellow callipers) with a crown-rump length measurement of $17.59 \mathrm{~mm}$ consistent with a gestational age of 8 weeks and 2 days. 


\section{Patient's perspective}

My case shows identical twinning even after transferring a single embryo.

\section{Learning points}

- Monozygotic twinning occurs more frequently in in vitro fertilisation pregnancies when compared with the general population.

- Single embryo transfer at blastocyst stage and frozen embryo cycles are independently associated with monozygotic twinning.

occur in up to $12.6 \%$ of IVF pregnancies, it is currently unknown whether PGT-A independently increases monozygotic twinning or vanishing twins in single blastocyst transfers. ${ }^{3}$

It is also important to acknowledge the possibility of multiple pregnancies in single embryo transfer cycles due to concomitant natural conception. Spontaneous ovulation due to possible bioaccumulation of clomiphene citrate or gonadotropins with unprotected intercourse during an IVF or frozen embryo treatment cycle may result in unexpected multiple pregnancies. This scenario is highly unlikely in the current case given that the patient was treated with leuprolide acetate to suppress natural ovulation.

Informed consent was obtained from the patient for the publication of this report.

Contributors NS and CN: manuscript preparation and literature search. NP: patient's clinical care, manuscript.

Funding The authors have not declared a specific grant for this research from any funding agency in the public, commercial or not-for-profit sectors.

Competing interests None declared.

Patient consent for publication Obtained.

Provenance and peer review Not commissioned; externally peer reviewed.

\section{REFERENCES}

1 Kanter JR, Boulet SL, Kawwass JF, et al. Trends and correlates of monozygotic twinning after single embryo transfer. Obstet Gynecol 2015;125:111-7.

2 Ikemoto Y, Kuroda K, Ochiai A, et al. Prevalence and risk factors of zygotic splitting after 937848 single embryo transfer cycles. Hum Reprod 2018;33:1984-91.

3 Márton V, Zádori J, Kozinszky Z, et al. Prevalences and pregnancy outcome of vanishing twin pregnancies achieved by in vitro fertilization versus natural conception. Fertil Steril 2016;106:1399-406.

Copyright 2020 BMJ Publishing Group. All rights reserved. For permission to reuse any of this content visit

https://www.bmj.com/company/products-services/rights-and-licensing/permissions/

BMJ Case Report Fellows may re-use this article for personal use and teaching without any further permission.

Become a Fellow of BMJ Case Reports today and you can:

- Submit as many cases as you like

- Enjoy fast sympathetic peer review and rapid publication of accepted articles

- Access all the published articles

Re-use any of the published material for personal use and teaching without further permission

\section{Customer Service}

If you have any further queries about your subscription, please contact our customer services team on +44 (0) 2071111105 or via email at support@bmj.com.

Visit casereports.bmj.com for more articles like this and to become a Fellow 